\title{
Monitoring and evaluation of breast cancer screening programmes: selecting candidate performance indicators
}

\author{
Sergei Muratov', Carlos Canelo-Aybar², Jean-Eric Tarride', Pablo Alonso-Coello², Nadya Dimitrova ${ }^{3 *}$,
} Bettina Borisch ${ }^{4}$, Xavier Castells ${ }^{5}$, Stephen W. Duffy ${ }^{6}$, Patricia Fitzpatrick ${ }^{7,8}$, Markus Follmann ${ }^{9}$, Livia Giordano ${ }^{10}$, Solveig Hofvind ${ }^{11}$, Annette Lebeau ${ }^{12}$, Cecily Quinn ${ }^{13}$, Alberto Torresin ${ }^{14}$, Claudia Vialli ${ }^{3}$, Sabine Siesling ${ }^{15,16}$, Antonio Ponti ${ }^{10}$, Paolo Giorgi Rossi ${ }^{17}$, Holger Schünemann ${ }^{1}$, Lennarth Nyström ${ }^{18}$, Mireille Broeders ${ }^{19^{*}}$ (I) and On behalf of the ECIBC contributor group

\begin{abstract}
Background: In the scope of the European Commission Initiative on Breast Cancer (ECIBC) the Monitoring and Evaluation (M\&E) subgroup was tasked to identify breast cancer screening programme (BCSP) performance indicators, including their acceptable and desirable levels, which are associated with breast cancer (BC) mortality. This paper documents the methodology used for the indicator selection.

Methods: The indicators were identified through a multi-stage process. First, a scoping review was conducted to identify existing performance indicators. Second, building on existing frameworks for making well-informed health care choices, a specific conceptual framework was developed to guide the indicator selection. Third, two group exercises including a rating and ranking survey were conducted for indicator selection using pre-determined criteria, such as: relevance, measurability, accurateness, ethics and understandability. The selected indicators were mapped onto a BC screening pathway developed by the M\&E subgroup to illustrate the steps of BC screening common to all EU countries.
\end{abstract}

Results: A total of 96 indicators were identified from an initial list of 1325 indicators. After removing redundant and irrelevant indicators and adding those missing, 39 candidate indicators underwent the rating and ranking exercise. Based on the results, the M\&E subgroup selected 13 indicators: screening coverage, participation rate, recall rate, breast cancer detection rate, invasive breast cancer detection rate, cancers $>20 \mathrm{~mm}$, cancers $\leq 10 \mathrm{~mm}$, lymph node status, interval cancer rate, episode sensitivity, time interval between screening and first treatment, benign open surgical biopsy rate, and mastectomy rate.

(Continued on next page)

\footnotetext{
* Correspondence: Nadya.Dimitrova@ec.europa.eu;

Mireille.Broeders@radboudumc.nl

${ }^{3}$ European Commission, Joint Research Centre, Via E. Fermi 2749 - TP 127,

I-21027 Ispra, VA, Italy

${ }^{19}$ Radboud Institute of Health Sciences, Radboud University Medical Center, Nijmegen, Netherlands

Full list of author information is available at the end of the article
}

(C) The Author(s). 2020 Open Access This article is licensed under a Creative Commons Attribution 4.0 International License, which permits use, sharing, adaptation, distribution and reproduction in any medium or format, as long as you give appropriate credit to the original author(s) and the source, provide a link to the Creative Commons licence, and indicate if changes were made. The images or other third party material in this article are included in the article's Creative Commons licence, unless indicated otherwise in a credit line to the material. If material is not included in the article's Creative Commons licence and your intended use is not permitted by statutory regulation or exceeds the permitted use, you will need to obtain permission directly from the copyright holder. To view a copy of this licence, visit http://creativecommons.org/licenses/by/4.0/ The Creative Commons Public Domain Dedication waiver (http://creativecommons.org/publicdomain/zero/1.0/) applies to the data made available in this article, unless otherwise stated in a credit line to the data. 
(Continued from previous page)

Conclusion: This systematic approach led to the identification of 13 BCSP candidate performance indicators to be further evaluated for their association with BC mortality.

Keywords: Breast neoplasms/diagnostic imaging*, Early detection of Cancer*/methods, Female, Mass screening/ methods, Programme evaluation, Quality indicators, Health care/standards*

\section{Background}

Breast cancer $(\mathrm{BC})$ remains a major public health issue in the European Union (EU) [1-3]. Currently, the vast majority of European countries operate populationbased breast cancer screening programmes (BCSPs) [4]. However, the considerable variation in both incidence and mortality rates between European countries suggests inequalities in care among European citizens, including performance of the BCSPs [5].

Monitoring and evaluation of BCSPs is necessary to ensure that the programmes are as effective as expected. The basis for these activities is described in the European Guidelines for Quality Assurance in Breast Cancer Screening and Diagnosis $[6,7]$. In general, a distinction should be made between 1) monitoring the performance of the screening programme via performance indicators that reflect the provision and quality of the activities constituting the screening processes and 2) evaluation of the impact of a screening programme as a whole based on the main outcomes. Although some evidence exists for both aspects [4, 7-10], the association between BCSP performance indicators and important patient outcomes, such as BC mortality, quality of life and undesirable effects, is poorly explored. If established, this would allow for more efficient monitoring and evaluation of the BCSPs. However, the few studies that have examined the association are limited in their methodologies, in the number of performance indicators evaluated, and report conflicting results $[1-14]$.

In this context, the European Commission Initiative on Breast Cancer (ECIBC) aims to enhance the quality of $\mathrm{BC}$ care in Europe by developing a quality assurance (QA) scheme for the full spectrum of BC services [15, 16] and provides evidence-based guidelines for screening and diagnosis. The European Commission's Joint Research Centre (JRC) is responsible for the overall scientific coordination and funding, also ensuring conflict of interest management, and transparent reporting of the activities. As part of the work, the Guidelines Development Group's (GDG) subgroup on Monitoring and Evaluation (M\&E) was tasked to identify potential BCSP performance indicators and their acceptable and desirable levels using a systematic and evidence-based approach. The main objective was to provide guidance on the use of BCSP performance indicators, monitoring of which would evaluate the effectiveness of breast cancer screening related to breast cancer mortality reduction a certain number of years after implementation. The purpose of this paper is to document the methodology used to identify candidate BCSP performance indicators, which will then be further evaluated for association between each one of them and BC mortality. The methodology for the latter will be described in another paper.

\section{Methods}

The final list of potential performance indicators was identified through a multi-stage process: 1) conduct of a scoping review to identify a list of existing performance indicators; 2) development of a conceptual framework to inform indicator selection; 3 ) conduct of a survey among the $M \& E$ subgroup members to select a list of candidate performance indicators according to pre-agreed criteria; and 4) description of a $\mathrm{BC}$ screening and diagnostic pathway to facilitate the mapping of the indicators along the key steps. The process was guided by a pre-defined study protocol (unpublished) and completed in 2016-18. Representing various EU states, the M\&E subgroup consists of European experts in breast cancer screening and diagnosis. To ensure synergy and consistency in the input of ECIBC working groups, two members of ECIBC's Quality Assurance Scheme Development Group (QASD G) for the European quality assurance scheme in breast cancer services were included in the M\&E subgroup as contributors. In addition, the selection of the candidate indicators was discussed at meetings of the full GDG and QASDG.

\section{Scoping review of performance indicators}

First, a search in MEDLINE and EMBASE databases was conducted by Cochrane Iberoamerica to identify publications in English that report performance indicators in the context of BCSPs (Additional file 1). Editorials, debate articles, or conference abstracts were excluded. The key inclusion criterion was that the data must originate from population-based BCSPs implemented at regional or country level. After an initial calibration using a sample of the retrieved records, two reviewers each screened half of the study titles and abstracts for potential eligibility, according to the inclusion criterion. The reviewers then independently confirmed the eligibility based on the full text assessment. In case of discordance, consensus was reached by discussion or involving a third 
reviewer. A PRISMA flowchart was used to report the search flow [17].

Second, an extensive review of grey literature and expert consultation was carried out to identify performance indicators recommended and/or reported by BCSPs and national/regional authorities in charge of those programmes. Following consultations with M\&E subgroup members, a sample of 12 countries (Australia, Canada, Denmark, Finland, Germany, Italy, Netherlands, New Zealand, Norway, Spain, Sweden, UK) was selected based on the following criteria: a) national populationbased BCSPs or national evaluation reports of regional population-based screening programmes exist, and b) history ( $\geq 10$ years) of implementation of their BCSP. Websites of the ministries of health or governmental offices in charge of the BCSPs were reviewed. The search results were shared with the M\&E subgroup members with a request to submit any additional relevant documents that were not captured in the search. For each country, the most recently published documents were considered which either explicitly described recommended indicators for monitoring the BCSPs processes and outcomes or reported the results of performance indicator used. Finally, a list of definitions was compiled for those indicators which were identified in the eligible studies or originating from specific BCSPs' documents.

\section{Development of a conceptual framework}

Building on existing frameworks for making wellinformed health care choices $[15,18,19]$, a specific conceptual framework was adopted to guide the selection of potential performance indicators from those identified by the scoping review. The European QA Scheme served as the basis for the framework [15]. It describes several domains such as clinical effectiveness, safety, personal empowerment, and facilities and workforce that are intended to guide the quality evaluation of the breast cancer services. The European Observatory seminal document on assuring healthcare quality in the EU provided a number of other possible domains for our consideration such as equity, responsiveness and efficiency [19]. We also examined parameters of the Evidence to Decision framework that supports decision making in public health by assessing different options using explicit criteria [18].

\section{Selection of potential performance indicators}

Selection of the final list of potential BCSP performance indicators was completed by means of two group exercises. First, all the identified candidates were grouped into indicator categories that generally represented certain steps along the breast cancer screening and diagnostic pathway (i.e., attendance, recall, screen-detected and interval breast cancer detection, sensitivity, mammographic quality, time requirements, biopsy, and treatment) (Additional file 1). During an in-person meeting of the M\&E subgroup (Ispra, Italy, September 18, 2017), irrelevant and redundant indicators were removed from the initial list of performance indicators identified by the literature review. Irrelevant indicators were defined as those without sound clinical and/or empirical rationale, whereas indicators semantically very close to one another or those calculated in a very similar way were considered redundant. The decision to remove or retain an indicator was made by consensus among all subgroup members present at the meeting.

Second, a rating and ranking survey was created to assess the remaining performance indicators against preagreed criteria to facilitate the selection and make the process consistent. Table 1 presents the definition of the five criteria used in the survey (relevant, measurable, accurate, ethical and understandable). They were developed based on the criteria used for the selection of requirements for the European QA scheme [15], and the experience of other international organisations engaged in monitoring and evaluation activities in health care in general or in breast cancer specifically [20-23]. The M\&E subgroup members discussed the criteria in light of their knowledge, analytical experience and data availability. Once the criteria were agreed upon, a weblink to complete the rating and ranking survey was sent to all the subgroup members via the SurveyMonkey platform (SurveyMonkey Inc., San Mateo, California, USA, www. surveymonkey.com). Participants were asked to rate each performance indicator identified by the literature searches based on the five criteria using a scale from 0 (completely disagree) to 10 (completely agree). For every indicator the average rating score and its standard deviation of each criterion were computed. Following the survey, the M\&E subgroup of 20 members re-convened

Table 1 Selection criteria for the rating and ranking exercise RELEVANT - An adequate indicator must have sound clinical and/or empirical rationale for its use. It represents an important aspect of breast cancer screening, gives useful information to different practice and policy stakeholders and stimulates efficient actions.

MEASURABLE - The data required to assess the indicator must be available and easily accessible.

ACCURATE - An adequate indicator should have a relatively large variation in the delivery of (sub)-processes of care to women between services and/or between Member States that is not due to random variation or female (client) characteristics.

ETHICAL - Collection, treatment and analysis of indicator data respects individual rights of confidentiality, freedom of choice in providing data and informed consent about the nature and implications of data provided.

UNDERSTANDABLE - An indicator has to be simple. Its interpretation should be easy and understandable by the majority of the population, not only by experts and stakeholders. 
to review the responses in an in-person meeting and make the final selection.

Some breast cancer screening categories included more than one performance indicator; e.g. in the category "Attendance", there were invitation coverage, participation rate, and screening coverage. In these cases, participants were asked to rank indicators within the category by appropriateness for inclusion on the final list of candidate BCSP performance indicators. A weighted average score was calculated for each ranked indicator. If there was only one indicator per category, participants were asked whether the indicator was appropriate for inclusion on the final list. For such indicators the proportion of positive and negative responses was calculated. As such, performance indicator selection was guided by the average rating score, weighted ranking score and/or the proportion of positive responses.

\section{BC screening and diagnostic pathway}

The final list of candidate indicators was mapped onto a breast cancer screening pathway that was developed by the $M \& E$ subgroup simultaneously to the indicator selection process (Fig. 1). This pathway illustrates the key steps of BCSP common to all EU countries and organises them in a logical order. The structure builds on the pathway presented by the European QA scheme and several other pathways published previously [15, 20, 24]. Of note, it was decided that the pathway for this exercise would predominantly cover BC screening, diagnosis and primary treatment steps.

\section{Results}

Scoping review

A total of 1399 unique citations were retrieved from the two databases (MEDLINE, EMBASE). 1258 citations were excluded based on title or abstract review. After reviewing the full texts of 141 citations, 76 studies were included for final review. Figure 2 presents the PRISMA flow chart for the selection process. All publications originated from the period 1994-2017 mainly from European Union countries, with the exception of three studies from Australia and four from Canada. The search of the grey literature yielded four BC screening guidance manuals (the European Union, Australia, Italy and England) and eight BCSP reports (Australia, Canada (2), Denmark, New Zealand, Scotland, Wales and the European Commission) which recommended or used process indicators for monitoring BCSP activities.

From the results of this published and grey literature review, an initial list of 1325 performance indicators was prepared. These indicators were reviewed by the panel of subgroup members to identify duplicates. A total of 96 unique indicators were finally retained.

\section{Performance indicators selection}

Based on previous conceptual frameworks, the following domains to identify performance indicators for BCSPs

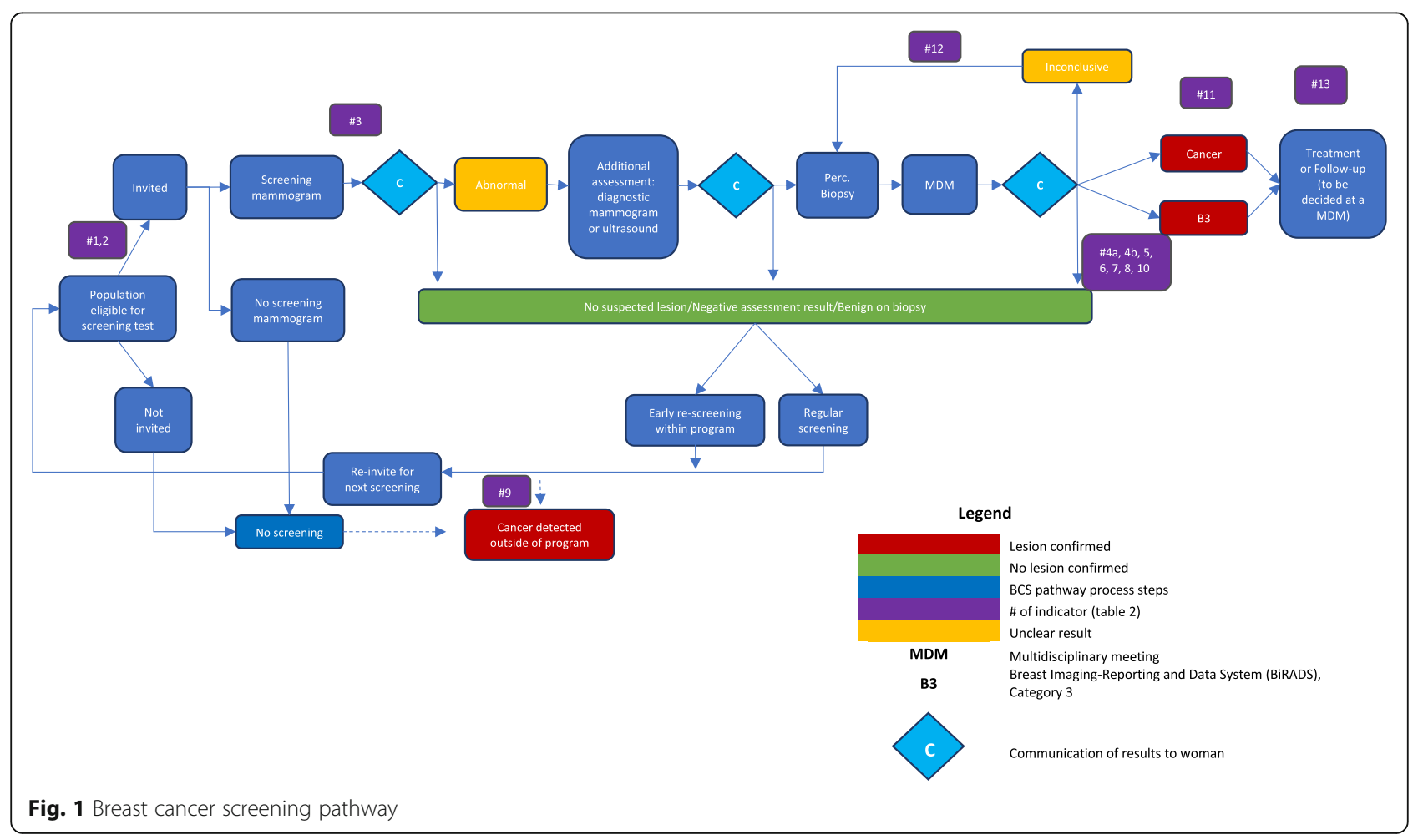




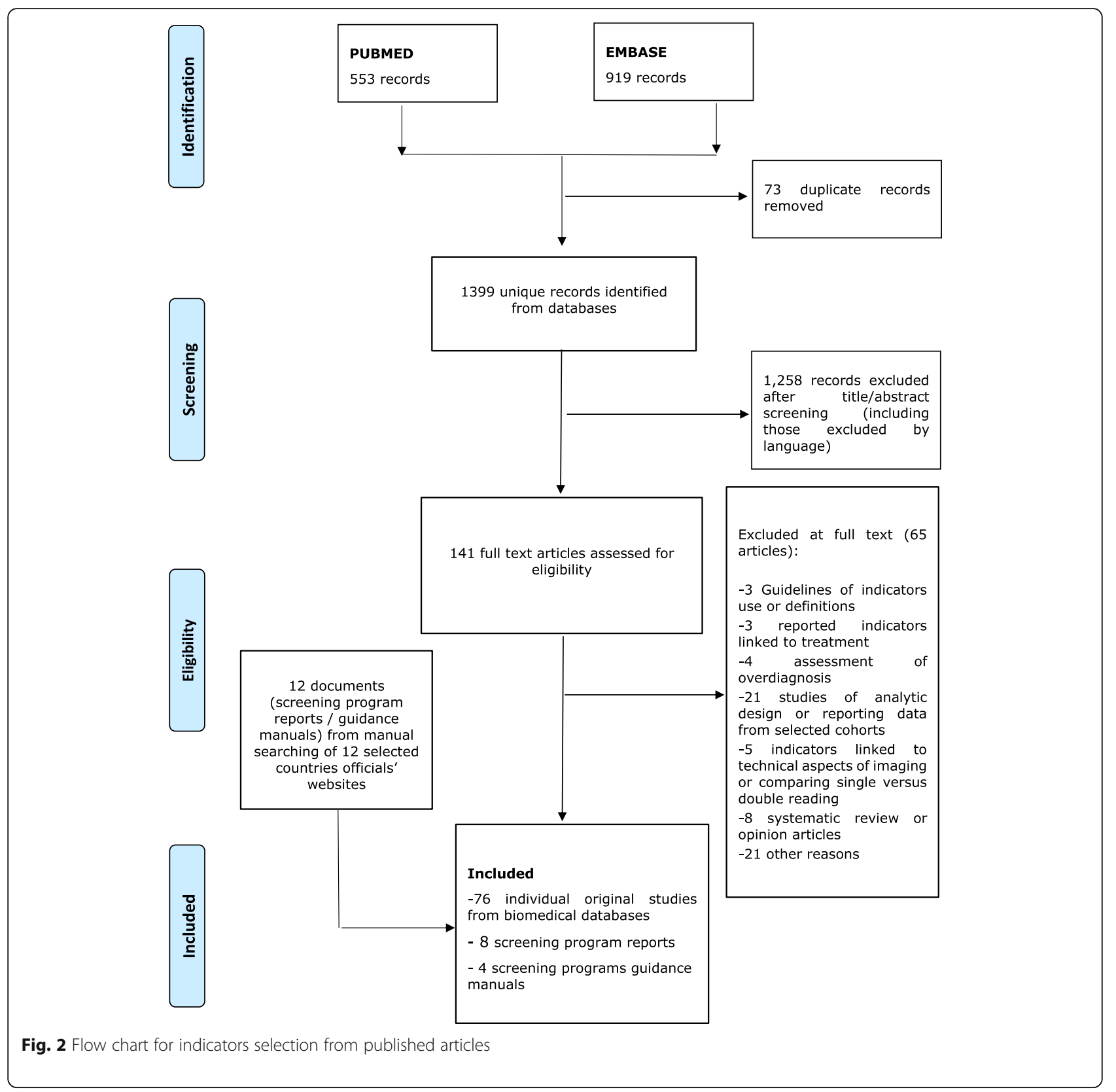

were considered: clinical effectiveness, safety, facilities/ resources/workforce, personal empowerment and experience, equity and cost-effectiveness. Clinical effectiveness was considered by the M\&E subgroup as the most important domain, which is commonly supported by evidence (Additional file 1).

Out of the 96 identified indicators, 63 indicators were eliminated as irrelevant or redundant during the first in-person group exercise (Ispra, Italy, September 18, 2017) (Additional file 1). The subgroup modified the definition of three indicators (invitation coverage, interval cancer detection over expected ratio, false negative assessment after recall), added two new indicators (BC detection rate by subtype and time interval between screening and first treatment) that were not captured by the search, and one indicator (breast cancer detection rate) was split into two (one for initial and subsequent screenings). As a result, the group arrived at 39 indicators in total belonging to eight categories: attendance, recall, screen-detected and interval breast cancer, sensitivity, time requirements, biopsy, and primary treatment. 
All 39 performance indicators (Additional file 1) were included into the online rating and ranking survey that was completed by the subgroup members $(n=20)$ between 6 and 15 November, 2017. The response rate was $65 \%$ (13 out of 20 experts), although only 11 (55\%) respondents provided a complete response. Table 2 illustrates the results of the exercise using the example of recall. There were five indicator definitions in the recall category under review: recall rate, positive predictive value of recall, false positive rate, early recall rate, and false negative assessment after recall. By rating, the recall rate definition received the highest score across all 5 criteria, with the mean score ranging from 9.4 to 9.7. When ranking the five definitions, the recall rate definition was ranked $\# 1$ by $90 \%$ of the participants and had the highest weighted score. Full survey data on all 39 indicators is available upon request from the authors.
Results were reviewed by the subgroup at the next meeting (Ispra, Italy, November 23, 2017) and 13 candidate performance indicators were finally selected. Those were: 1) screening coverage, 2) participation rate, 3) recall rate; 4) breast cancer detection rate, 5) invasive breast cancer detection rate; 6) cancers $>20 \mathrm{~mm}$; 7) cancers $\leq 10 \mathrm{~mm}$; 8) lymph node status; 9) interval cancer rate; 10) episode sensitivity; 11) time interval between screening and first treatment; 12) benign open surgical biopsy rate; and 13) mastectomy rate. Table 3 presents the final list of 13 performance indicators, their definitions and the domain of the conceptual framework they represent. The indicators were mapped on the BC screening pathway. Together, all 13 indicators cover several key steps along the pathway (Fig. 1) and address all the woman-important outcomes included in the new European guidelines Evidence to Decision framework,

Table 2 Rating and ranking exercise results - the example of recall rate

\begin{tabular}{|c|c|c|c|c|c|}
\hline \multicolumn{6}{|l|}{ A. Definitions of indicators under review } \\
\hline Name of indicators & \multicolumn{3}{|l|}{ Numerator } & \multicolumn{2}{|l|}{ Denominator } \\
\hline Recall rate & \multicolumn{3}{|c|}{$\begin{array}{l}n^{0} \text { of women recalled for further assessment based on a } \\
\text { positive screening examination }\end{array}$} & \multicolumn{2}{|c|}{$\mathrm{n}^{\circ}$ of women screened } \\
\hline Positive predictive value of recall & \multicolumn{3}{|c|}{$\mathrm{n}^{\circ}$ of breast cancers detected } & \multicolumn{2}{|c|}{$\begin{array}{l}\mathrm{n}^{\circ} \text { of women recalled for further } \\
\text { assessment }\end{array}$} \\
\hline False positive rate & \multicolumn{3}{|c|}{$\begin{array}{l}\mathrm{n}^{\circ} \text { of women recalled for further assessment with no cancer } \\
\text { diagnosis }\end{array}$} & \multicolumn{2}{|c|}{$n^{\circ}$ of women screened } \\
\hline Early recall rate & \multicolumn{3}{|c|}{$\begin{array}{l}\mathrm{n}^{\circ} \text { of women invited to undergo a re-screen at an interval less } \\
\text { than the routine screening interval }\end{array}$} & \multicolumn{2}{|c|}{$n^{\circ}$ of women screened } \\
\hline False negative assessment after recall & \multicolumn{3}{|c|}{$\begin{array}{l}\mathrm{n}^{\circ} \text { of women diagnosed with breast cancer after recall and } \\
\text { negative further assessment }\end{array}$} & \multicolumn{2}{|c|}{$\mathrm{n}^{\circ}$ of women screened } \\
\hline \multicolumn{6}{|l|}{ B. Results } \\
\hline \multirow[t]{2}{*}{ Indicator selection criteria } & \multicolumn{5}{|l|}{ Rating $^{\mathrm{a}}$ (mean, SD) } \\
\hline & Early recall rate & Recall rate & False negative & False positive & Positive predictive value \\
\hline Relevant & $7.5(2.8)$ & $9.4(0.7)$ & $8.3(1.2)$ & $9.1(1.3)$ & $9.0(1.0)$ \\
\hline Measurable & $7.4(2.5)$ & $9.5(0.9)$ & $6.6(2.5)$ & $9.4(0.7)$ & $9.5(0.8)$ \\
\hline Accurate & $6.9(3.1)$ & $9.4(1.0)$ & $6.9(1.9)$ & $9.4(0.8)$ & $9.0(1.3)$ \\
\hline Ethical & $9.3(0.8)$ & $9.7(0.5)$ & $9.4(0.7)$ & $9.7(0.5)$ & $9.7(0.5)$ \\
\hline Understandable & $8.7(1.6)$ & $9.4(0.8)$ & $7.9(3.2)$ & $9.0(1.0)$ & $9.3(1.0)$ \\
\hline Rank & \multicolumn{5}{|l|}{ Ranking } \\
\hline 1 & & 9 & & 2 & \\
\hline 2 & 1 & 1 & & 4 & 5 \\
\hline 3 & \multicolumn{2}{|l|}{2} & 3 & 3 & 2 \\
\hline 4 & \multicolumn{3}{|l|}{2} & & 1 \\
\hline 5 & \multicolumn{3}{|l|}{4} & & 1 \\
\hline Not applicable & \multicolumn{2}{|l|}{2} & 2 & \multicolumn{2}{|l|}{2} \\
\hline No of participants ranking & 11 & 10 & 11 & \multicolumn{2}{|l|}{11} \\
\hline Weighted ranking score & 2.0 & 4.9 & 2.4 & 3.6 & 3.2 \\
\hline
\end{tabular}

a - a scale of 0 to 10 was used for rating $S D$ standard deviation;

Total number of participants was 13,2 of whom provided only partial responses 
Table 3 Final list of candidate performance indicators

\begin{tabular}{llll}
\hline Indicator & Definition & $\begin{array}{l}\text { Conceptual } \\
\text { framework } \\
\text { domain }\end{array}$ & $\begin{array}{l}\text { Indicator interpretation } \\
\text { 1. Screening coverage }\end{array}$ \\
& $\begin{array}{l}\text { NUMERATOR: } \mathrm{n}^{\circ} \text { of women screened } \\
\text { DENOMINATOR: } \mathrm{n}^{\circ} \text { of eligible (or target) women } \\
\text { within a given period }\end{array}$ & $\begin{array}{l}\text { Clinical } \\
\text { effectiveness } \\
\text { Facilities/ } \\
\text { resources/ }\end{array}$ & $\begin{array}{l}\text { Measures the test coverage in the population. } \\
\text { It should primarily be used for organised } \\
\text { screening, but it can also include tests } \\
\text { performed in the opportunistic setting. The } \\
\text { aim is to maximise the value of the indicator, } \\
\text { but it can only be applied to ages for which a }\end{array}$ \\
& $\begin{array}{l}\text { workforce } \\
\text { Personal } \\
\text { empowerment }\end{array}$ & $\begin{array}{l}\text { strong recommendation for breast cancer } \\
\text { and experience }\end{array}$
\end{tabular}

\section{Participation rate \\ NUMERATOR: $n^{\circ}$ of women screened DENOMINATOR: $n^{\circ}$ of women invited}

3. Recall rate

\section{Breast cancer detection rate $(4 a$ : initial and $4 \mathrm{~b}$ : subsequent screenings)}

\section{Invasive breast cance detection rate}

6. Cancers $>20 \mathrm{~mm}$

7. Cancers $\leq 10 \mathrm{~mm}$

9. Interval cancer rate

10. Episode sensitivity

11. Time interval between screening and first treatment

12. Benign open surgical biopsy rate screen-detected detected detected

detected screening round INATOR: $n^{\circ}$ of all cancers detected percentile)
NUMERATOR: $n^{\circ}$ of women undergoing further assessment for medical reasons based on a positive screening or on recall)

DENOMINATOR: $n^{\circ}$ of women screened

NUMERATOR: $n^{\circ}$ of cancers screen-detected DENOMINATOR: $n^{\circ}$ of women screened

NUMERATOR: $\mathrm{n}^{\circ}$ invasive screen-detected cancers DENOMINATOR: $n^{\circ}$ of women screened

NUMERATOR: $\mathrm{n}^{\circ}$ of invasive cancers $>20 \mathrm{~mm}$ screen-detected DENOMINATOR: $n^{\circ}$ of women screened screening examination (either on the same day as

Clinical

effectiveness

Equity

Personal

empowerment and experience

Clinical

effectiveness

Facilities/

resources/

workforce

Clinical

effectiveness

Clinical effectiveness

Clinical effectiveness

NUMERATOR: $\mathrm{n}^{\circ}$ of invasive cancers $\leq 10 \mathrm{~mm}$ DENOMINATOR: $n^{\circ}$ of invasive cancers screen-

NUMERATOR: $n^{\circ}$ of node-negative cancers screen-

DENOMINATOR: $n^{\circ}$ invasive cancers screen-

NUMERATOR: $n^{\circ}$ of interval cancers DENOMINATOR: $\mathrm{n}^{\circ}$ of screened negative women at the last

NUMERATOR: $n^{\circ}$ screen-detected cancers DENOM-

Median number of days between screening and start of first treatment (10th percentile - 90th

NUMERATOR: $n^{\circ}$ of women found not to have invasive cancer or DCIS after an open surgical

Clinical effectiveness
Clinical effectiveness effectiveness

Clinical effectiveness

Clinical effectiveness, Facilities/ resources/ workforce Equity

Clinical effectiveness

The aim is to maximise the value of the indicator, but it can only be applied to ages for which a strong recommendation for breast cancer screening has been given.

Directly and timely measure the assessment workload and indirectly measure the false positive rates since cancers are a minority of recalls. High values indicate high false positive rates and should therefore raise concern.

Indirect measure of screening sensitivity. Influenced by the underlying incidence and is higher in the prevalence (first) round. Geographical comparisons and trends should take into account these two determinants.

Same as for the breast cancer detection rate.

Diameter is a strong prognostic factor. Screening should act by reducing incidence of large cancers. A reduction in the proportion of large cancers is expected in women that have been already screened. Proportion during prevalence (first) round can be considered only to set a baseline, not to measure effectiveness.

Indirect indicator of screening sensitivity. Reduction of the proportion of small screendetected cancer among already screened women can be an early sign of loss in sensitivity. It is lower in the prevalence (first) round.

Lymph node status is a strong prognostic factor. Screening showed efficacy in reducing the incidence of lymph node positive cancers. Furthermore, lymph node status influences the choice of treatment determining the use of chemotherapy or not in some cases.

Direct measure of screening sensitivity. Influenced by the underlying incidence and the screening interval.

Direct measure of screening sensitivity. May be influenced by screening round, overestimating sensitivity during prevalence (first) round.

Measure the ability of the organisation to minimise the time required to identify, assess and treat cancers. Directly associated with women's anxiety and, for extreme screening intervals. May reduce effectiveness because of cancer progression.

Direct measure of undesirable effects. Even if some of the benign lesions are treated 
Table 3 Final list of candidate performance indicators (Continued)

\begin{tabular}{|c|c|c|c|}
\hline Indicator & Definition & $\begin{array}{l}\text { Conceptual } \\
\text { framework } \\
\text { domain }\end{array}$ & Indicator interpretation \\
\hline & $\begin{array}{l}\text { biopsy } \\
\text { DENOMINATOR: } n^{\circ} \text { of women screened }\end{array}$ & Safety & because of their risk to progress to cancer. \\
\hline 13. Mastectomy rate & $\begin{array}{l}\text { NUMERATOR: } n^{\circ} \text { of women with mastectomy } \\
\text { DENOMINATOR: } n^{\circ} \text { of women screened }\end{array}$ & $\begin{array}{l}\text { Clinical } \\
\text { effectiveness } \\
\text { Safety }\end{array}$ & $\begin{array}{l}\text { Direct measure of the impact on treatment } \\
\text { invasiveness. Identifying cancer at earlier } \\
\text { stages should allow more conservative } \\
\text { treatments. }\end{array}$ \\
\hline
\end{tabular}

except overdiagnosis (Additional file 1) [25]. Additional file 1 shows the number of performance indicators that were identified at each key step of the selection process. Of note, this process and its results were presented to the entire GDG and QASDG.

\section{Discussion}

In this paper, we have described the identification of candidate BCSPs performance indicators using a systematic process. There is a substantial overlap in BC screening processes selected for evaluation by our subgroup members and reports from other international BCSPs $[20,26]$. Even if indicator definitions do not match precisely across various BCSPs, the programmes tend to focus on a small group of categories such as participation rate, cancer detection rates, including interval cancer rate, tumor size and time intervals. Further, the methodology for selecting performance indicators is consistent with previous research [27-29]. It consisted of iterative rating rounds of prioritisation with feedback given to the participants in face-to-face meetings. The addition of a ranking step was a novel modification. It allowed direct comparison and prioritisation of similar indicators within one indicator category. It also provided the subgroup with additional information to consider when making the final inclusion decision: a subset of indicators (e.g. proportion of tumours of various grade) was, for example, removed from further consideration because the respondents explicitly voted them nonapplicable for monitoring and evaluation purposes.

Key strengths of this research are threefold. First, the set of performance indicators was identified using a systematic and methodologically rigorous approach. Second, the rating and ranking exercise proved helpful in facilitating indicator elimination. Third, the focused range of selected indicators can contribute to a better uptake of monitoring and evaluation activities across EU screening programmes.

We also note limitations. The response rate for the rating and ranking survey was acceptable but not as high as expected, although the vast majority of the participants provided a complete response. However, the purpose of the survey was to facilitate decision making. As such, the survey results were reviewed by all the M\&E subgroup members at an in-person meeting that followed the survey. This allowed every member an opportunity to provide feedback, take part in the deliberations, and contribute to indicator selection. Further, despite the inclusion of a number of patient-important outcomes (e.g., breast cancer mortality, breast cancer incidence, quality of life, false positive), the list does not fully capture overdiagnosis and overtreatment. For the first, measuring overdiagnosis has been challenging even in trials [30] and large observational studies with long follow-up [31], thus finding operative measures for a timely monitoring seems conceptually impossible. For the latter, the indicator set covers invasiveness of treatment (i.e., mastectomy rate) and also has an indicator that is associated with the decision for chemotherapy (i.e. lymph node status).

\section{Conclusion}

A systematic approach was employed to identify 13 BCSP candidate performance indicators. By documenting the process we facilitate its replicability on a wider scale. As such, this systematic and transparent process can be applied to developing indicators for other cancer and non-cancer programmes, as needed. However, this selection process should not be considered as complete without establishing the relationship between the indicators, aimed at measuring BCSP effectiveness, and breast cancer mortality. With the very limited evidence from randomised clinical trials as well as observational studies available [11-14], a methodology must be developed to measure these associations, as well as to determine, where possible, the acceptable and desirable levels of each of these performance indicators, or to determine whether benchmarking and trend monitoring are the only ways to interpret them. The methods and results of such assessment, which is ongoing (results expected in early 2021), will be described in another paper.

\section{Supplementary information}

Supplementary information accompanies this paper at https://doi.org/10. 1186/s12885-020-07289-z.

Additional file 1: Appendix 1: Search strategy. Appendix 2: Number of performance indicators identified per stage. Appendix 3A: Candidate 
indicators identified by a systematic review: pre-selected for the rating and ranking survey $(n=39)$. Appendix 3B: Candidate indicators identified by a systematic review: irrelevant and/or redundant $(n=63)$. Appendix 4: Conceptual framework considerations.

\section{Abbreviations}

BC: Breast cancer; BCSP: Breast cancer screening programme; ECIBC : European Commission Initiative on Breast Cancer; EU: European Union; GDG: Guidelines Development Group; JRC: Joint Research Centre; QA: Quality Assurance; M\&E: Monitoring and Evaluation; UK: United Kingdom

\section{Acknowledgements \\ Not applicable.}

\section{Authors' contributions}

All authors (SM, JET, CC, MB, LN, ND, PGR, HS, SWD, PF, CQ, PAC, BB, XC, MF, $L G, S H, A L, A T, C V, S S, A P$ ) have contributed to study design, data analysis and interpretation, and manuscript review. SM, JET, CC, MB, LN, ND, PGR, HS contributed to data acquisition. SM, CC, and JET provided statistical analysis. SM, CC, and JET drafted the manuscript. MB, LN, CC, PGR, SWD, PF, CQ, ND provided editing of the manuscript. All the authors listed have reviewed and approved the final version of the manuscript.

\section{Funding}

The work was funded and coordinated by the European Commission, Joint Research Centre (JRC) in Ispra, Italy, in the scope of the project European Commission Initiative on Breast Cancer (ECIBC). Other than the contribution of individual JRC employees (Dr. Dimitrova, as outlined below), the funding agency did not have input into the design of the study and collection, analysis, and interpretation of data and in writing the manuscript. This research did not receive any specific grant from other sources.

\section{Availability of data and materials}

The datasets used and/or analysed during the current study are available from the corresponding author on reasonable request.

\section{Ethics approval and consent to participate}

Not applicable.

\section{Consent for publication}

Not applicable.

\section{Competing interests}

Dr. Muratov reports personal fees from Joint Research Center (European Commission), during the conduct of the study.

Dr. Canelo-Aybar, Dr. Alonso Coello and Dr. Valli report grants from Joint Research Center (European Commission), during the conduct of the study. Dr. Tarride reports other from European Union, during the conduct of the study; grants and other from Allergan, AstraZeneca, Amgen, CSL Behring, Janssen, Lilly, Novo Nordisk, Sage, Assurex/Myriad, Edwards Lifesciences, Pfizer, Roche, Merck, GlaxoSmithKline, Evidera, PCDI, CADTH., outside the submitted work:

Dr. Dimitrova reports Employee of the European Commission Joint Research Centre.

Dr. Lebeau reports non-financial support from European Commission, during the conduct of the study; and Dr. Lebeau is chair of the Breast Pathology Working Group of the German S3 Guidelines for the Early Detection, Diagnosis, Treatment and Follow up of Breast Cancer, a member of the Scientific Advisory Council for the Cooperation Alliance Mammography (Kooperationsgemeinschaft Mammographie GBR), Germany, member of the certification commission "breast cancer centres" as a representative of the German Society of Pathology and the Federal Association of German Pathologists, and board member of the German Society of Pathology and the German Society of Senology.

Dr. Giorgi Rossi reports the following activities:

05/2010-05/2012 - GISMa, Italy, -Type: NGO. Member of the coordinating group of the Italian Scientific Society on Mammographic screening. 20082012- ONS, Italy, -Type: Governmental. Member of the Steering committee of the National Centre for screening monitoring. 2012- today, - ONS, Italy -Type: Governmental. Consultant for the National Centre for screening monitoring (institutional duty, unpaid work). Sept/2018- today -Ispro, Toscana, Italy -Type: Governmental. Member of the Scientific committee (institutional duty, unpaid work). I have published opinions about the superiority of public, organised, population-based screening programs instead of opportunistic and private screening, according to the EC recommendations 2003/878/EC.

Besides corresponding individual COls, if any, Dr. Borisch, Dr. Broeders, Dr. Castells, Dr. Duffy, Dr. Fitzpatrick, Dr. Follmann, Dr. Giordano, Dr. Hofvind, Dr. Nyström, Dr. Quinn, Dr. Torresin, Dr. Schünemann (co-chair of the ECIBC GDG and co-chair of the GRADE working group) report being members of the ECIBC GDG; Dr. Ponti and Dr. Siesling are members of the ECIBC QASDG.

\section{Author details}

${ }^{1}$ Department of Health Research Methods, Evidence, and Impact, Faculty of Health Sciences, McMaster University, Hamilton, Ontario, Canada.

${ }^{2}$ lberoamerican Cochrane Center, Instituto de Investigación Biomédica Sant Pau (IIB Sant Pau-CIBERESP), Barcelona, Spain. ${ }^{3}$ European Commission, Joint Research Centre, Via E. Fermi 2749 - TP 127, I-21027 Ispra, VA, Italy. Institute of Global Health, University of Geneva, Geneva, Switzerland. IIMIM (Hospital del Mar Medical Research Institute), Barcelona, Spain. ${ }^{6}$ Queen Mary University of London, London, UK. ${ }^{7}$ National Screening Service, Dublin, Ireland. ${ }^{8}$ UCD School of Public Health, Physiotherapy \& Sports Science, Dublin, Ireland. ${ }^{9}$ German Cancer Society, Berlin, Germany. ${ }^{10} \mathrm{CPO}-$ Piedmont - AOU Città della Salute e della Scienza, Torino, Italy. ${ }^{11}$ Cancer Registry of Norway, Oslo, Norway. ${ }^{12}$ University Medical Center Hamburg-Eppendorf and Private Group Practice for Pathology, Hamburg, Germany. ${ }^{13}$ St. Vincent's University Hospital, Dublin, Ireland. ${ }^{14}$ ASST Grande Ospedale Metropolitano, Milan, Italy.

${ }^{15}$ Netherlands Comprehensive Cancer Organisation (IKNL), Utrecht, Netherlands. ${ }^{16}$ University of Twente, Enschede, Netherlands. ${ }^{17}$ AUSL Reggio Emilia, IRCCS, Reggio Emilia, Italy. ${ }^{18}$ Department of Epidemiology and Global Health, Umeå University, Umeå, Sweden. ${ }^{19}$ Radboud Institute of Health Sciences, Radboud University Medical Center, Nijmegen, Netherlands.

\section{Received: 17 January 2020 Accepted: 11 August 2020}

Published online: 24 August 2020

\section{References}

1. Carioli G, Malvezzi M, Rodriguez T, Bertuccio P, Negri E, La Vecchia C. Trends and predictions to 2020 in breast cancer mortality in Europe. Breast (Edinburgh, Scotland). 2017;36:89-95.

2. Ferlay J, Colombet M, Soerjomataram I, Dyba T, Randi G, Bettio M, et al. Cancer incidence and mortality patterns in Europe: estimates for 40 countries and 25 major cancers in 2018. Eur J Cancer. 2018;103:356-87.

3. European Cancer Information System. European Commission 2018 [Available from: https://ecis.jrc.ec.europa.eu/. Accessed 1 Nov 2019.

4. Ponti A, Anttila A, Ronco G, Senore C, Basu P, Segnan N, et al. Cancer screening in the European Union. Report on the implementation of the Council Recommendation on cancer screening. Brussels: International Agency for Research on Cancer; 2017.

5. Carvalho RN, Randi G, Giusti F, Martos C, Dyba T, Dimitrova N, Neamtiu L, Rooney R, Nicholson N, Bettio M. Socio-economic regional microscope series - Cancer burden indicators in Europe: insights from national and regional information. Luxembourg: Publications Office of the European Union; 2018.

6. Perry N, Broeders M, de Wolf C, Törnberg S, Holland R, von Karsa L. European Guidelines for Quality Assurance in Breast Cancer Screening and Diagnosis. 4th ed. Luxembourg: Office for Official Publications of the European Communities; 2006.

7. Broeders MJ, Scharpantgen A, Ascunce N, Gairard B, Olsen AH, Mantellini P, et al. Comparison of early performance indicators for screening projects within the European breast Cancer network: 1989-2000. Eur J Cancer Prev. 2005;14(2):107-16.

8. Biesheuvel C, Weigel S, Heindel W. Mammography Screening: Evidence, History and Current Practice in Germany and Other European Countries. Breast Care (Basel, Switzerland). 2011;6(2):104-9.

9. Broeders M, Moss S, Nystrom L, Njor S, Jonsson H, Paap E, et al. The impact of mammographic screening on breast cancer mortality in Europe: a review of observational studies. J Med Screen. 2012;19(Suppl 1):14-25.

10. Bento MJ, Goncalves G, Aguiar A, Castro C, Veloso V, Rodrigues V. Performance indicators evaluation of the population-based breast cancer 
screening programme in northern Portugal using the European guidelines. Cancer Epidemiol. 2015;39(5):783-9.

11. Chen TH, Yen AM, Fann JC, Gordon P, Chen SL, Chiu SY, et al. Clarifying the debate on population-based screening for breast cancer with mammography: a systematic review of randomized controlled trials on mammography with Bayesian meta-analysis and causal model. Medicine. 2017;96(3):e5684.

12. Morrell S, Taylor R, Roder D, Robson B, Gregory M, Craig K. Mammography service screening and breast cancer mortality in New Zealand: a National Cohort Study 1999-2011. Br J Cancer. 2017;116(6):828-39.

13. Sarkeala T. Performance and effectiveness of organised breast cancer screening in Finland. Acta Oncol (Stockholm, Sweden). 2008;47(8):1618.

14. Sarkeala T, Anttila A, Saarenmaa I, Hakama M. Validity of process indicators of screening for breast cancer to predict mortality reduction. J Med Screen. 2005;12(1):33-7.

15. EU, European Commission, Joint Research Center. European Quality Assurance scheme for Breast Cancer Services 2016 [Available from: https:/ ecibc.jrc.ec.europa.eu/quality-assurance. Accessed 1 Nov 2019.

16. Committee note. Council Conclusions on reducing the burden of cancer (9636/08): The Council of the European Union, Brussels; May 2008 [Available from: http://register.consilium.europa.eu/doc/srv?|=EN\&f=ST\%209636\%202 008\%20INIT. Accessed 1 Nov 2019.

17. Moher D, Liberati A, Tetzlaff J, Altman DG. Preferred reporting items for systematic reviews and meta-analyses: the PRISMA statement. J Clin Epidemiol. 2009;62(10):1006-12.

18. Alonso-Coello P, Schünemann HJ, Moberg J, Brignardello-Petersen R, Akl EA, Davoli M, et al. GRADE Evidence to Decision (EtD) frameworks: a systematic and transparent approach to making well informed healthcare choices. 1: Introduction. BMJ. 2016;353:i2016.

19. Legido-Quigley H, McKee M, Nolte E, Glinos AG. Assuring the quality of health care in the European Union: A case for action. Observatory Studies Series No.12. Bodmin: World Health Organization; 2008.

20. Canadian partnership against Cancer. Breast Cancer screening in Canada: monitoring and evaluation of quality indicators - results report, January 2011 to December 2012. Toronto: Canadian Partnership Against Cancer; 2017.

21. Canadian Partnership Against Cancer. Quality determinants and indicators for measuring colorectal Cancer screening program performance in Canada. Toronto: Canadian partnership against Cancer; 2012

22. Center for Health Policy. Center for Primary Care and Outcomes Research \& Battelle Memorial Institute. Quality Indicator Measure Development, Implementation, Maintenance, and Retirement (Prepared by Battelle, under Contract No. 290-04-0020). Rockville, MD: Agency for Healthcare Research and Quality; 2011.

23. Irish Health Information and Quality Authority. Guidance on Developing Key Performance Indicators and Minimum Data Sets to Monitor Healthcare Quality 2013 [Available from: https://www.hiqa.ie/reports-and-publications/ health-information/guidance-developing-key-performance-indicators-kpis-0. Accessed 1 Nov 2019.

24. Washington State Department of Health. Breast, Cervical and Colon Health Program Information for Providers: Breast care algorithm [Available from: https://www.doh.wa.gov/ForPublicHealthandHealthcareProviders/ PublicHealthSystemResourcesandServices/LocalHealthResourcesandTools/ BreastCervicalandColonHealth. Accessed 1 Nov 2019.

25. Schünemann HJ, Lerda D, Dimitrova N, Alonso-Coello P, Gräwingholt A, Quinn C, et al. Methods for development of the European Commission initiative on breast Cancer guidelines: recommendations in the era of guideline transparency. Ann Intern Med. 2019;171(4):273-80. https://doi.org/ 10.7326/M18-3445

26. Australian Institute of Health and Welfare. BreastScreen Australia monitoring report 2018. Canberra: AlHW; 2018.

27. Khare $S R$, Batist $G$, Bartlett $G$. Identification of performance indicators across a network of clinical cancer programs. Curr Oncol (Toronto, Ont). 2016;23(2):81-90.

28. Bradley NME, Robinson PD, Greenberg ML, Barr RD, Klassen AF, Chan YL, et al. Measuring the quality of a childhood Cancer care delivery System: quality Indicator development. Value Health. 2013;16(4):647-54.

29. Csanadi M, de Kok IM, Heijnsdijk EA, Anttila A, Heinavaara S, Pitter JG, et al. Key indicators of organized cancer screening programs: results from a Delphi study. J Med Screen. 2019;26:120-6.

30. Independent UK Panel on Breast Cancer Screening. The benefits and harms of breast cancer screening: an independent review. Lancet. 2012;380(9855): 1778-86.
31. Puliti D, Duffy SW, Miccinesi G, de Koning H, Lynge E, Zappa M, et al. Overdiagnosis in mammographic screening for breast cancer in Europe: a literature review. J Med Screen. 2012;19(Suppl 1):42-56.

\section{Publisher's Note}

Springer Nature remains neutral with regard to jurisdictional claims in published maps and institutional affiliations.
Ready to submit your research? Choose BMC and benefit from:

- fast, convenient online submission

- thorough peer review by experienced researchers in your field

- rapid publication on acceptance

- support for research data, including large and complex data types

- gold Open Access which fosters wider collaboration and increased citations

- maximum visibility for your research: over $100 \mathrm{M}$ website views per year

At BMC, research is always in progress.

Learn more biomedcentral.com/submissions 